\title{
CONSTITUCIÓN PENAL
Y TEORÍA DE LA PENA:
APUNTES SOBRE UNA
RELACIÓN NECESARIA
Y PROPUESTA PARA UN
POSIBLE CONTENIDO DESDE
LA PREVENCIÓN ESPECIAL*
}

\author{
Criminal Constitutions and \\ THEORY OF PUNISHMENT: NOTES ON \\ a Necessary Relationship and \\ Proposal for Possible Content on \\ Special Prevention
}

\author{
CONSTITUIÇÃO PENAL E TEORIA DA \\ PENA: ANOTAÇÕES SOBRE UMA RELAÇÃO \\ NECESSÁRIA E PROPOSTA PARA UM \\ POSSÍVEL CONTEÚDO A PARTIR DA \\ PREVENÇÃO ESPECIAL
}

MARIO DURÁN-MIGLIARDI**
* Este trabajo ha sido realizado en el marco del Proyecto Regular de Investigación Conicyt-Fondecyt 2012 no 1120150, titulado "El derecho penal constitucional como fundamento de los principios, instrumentos y fines del sistema penal. Concepto, alcance y limitaciones en Chile", de quien el autor es investigador responsable.
** Universidad de Atacama. Chile. mario.duran@uda.cl

RECIBIDO: 22 DE ENERO DE 2015. ENVÍO A PARES: 26 DE ENERO DE 2015 APROBADO POR PARES: 12 DE MARZO DE 2015. ACEPTADO: 23 DE MARZO DE 2015

DOI: $10.5294 / D I K A .2015 .24 .2 .4$

PARA CITAR ESTE ARTÍCULO / TO REFERENCE THIS ARTICLE / PARA CITAR ESTE ARTIGO DURÁN-MIGLIARDI, MARIO, "CONSTITUCIÓN PENAL Y TEORÍA DE LA PENA: APUNTES SOBRE UNA RELACIÓN NECESARIA Y PROPUESTA PARA UN POSIBLE CONTENIDO DESDE LA PREVENCIÓN ESPECIAL", EN DIKAION, 24-2 (2015), PP. 282-3O6. DOI: 10.5294/DIKA.2015.24.2.4 


\section{RESUMEN}

El presente trabajo postula la existencia, en toda sociedad democrática, de profundas conexiones entre la denominada constitución penal y la necesaria justificación teórica del castigo penal. Desde esta perspectiva, y luego de analizar el fundamento constitucional del derecho penal democrático, se estudia, a partir de una visión política-criminal, y en perspectiva constitucional, el posible rol que las teorías de prevención especial y el propio ideario resocializador pueden cumplir en este contexto.

\section{PALABRAS CLAVE}

Constitución penal; política criminal; teoría de la pena; prevención especial. 


\begin{abstract}
The article suggests the existence of profound connections, in every democratic society, between so-called criminal constitutions and the necessary theoretical justification for criminal punishment. From this perspective and after examining the constitutional basis of democratic criminal law, the possible role that theories of special prevention and re-socialization thinking can play in this context are analyzed based on a criminal-policy view and a constitutional perspective.
\end{abstract}

\title{
KEYWORDS
}

Criminal constitution; criminal policy; theory of punishment; special prevention. 


\section{RESUMO}

Este trabalho pressupõe a existência, em toda sociedade democrática, de profundas conexões entre a denominada constituição penal e a necessária justificativa teórica do castigo penal. Sob esse prisma, e após inquirir sobre o fundamento constitucional de direito penal democrático, analisa-se, a partir de uma visão político-criminal e em perspectiva constitucional, o possivel papel que as teorias de prevenção especial e o próprio ideário ressocializador podem desempenhar nesse contexto.

\section{PALAVRAS-CHAVE}

Constituição penal; política criminal; teoria da pena; prevenção especial. 
SUMARIO: INTRODUCCIÓN: TESIS Y CONTENIDO DE LA DENOMINADA CONSTITUCIÓN PENAL Y SU VINCULACIÓN CON LOS FINES DE LA PENA; 1. LA PREVENCIÓN ESPECIAL O EL IDEAL RESOCIALIZADOR COMO PRINCIPIO LIMITADOR DEL IUS PUNIENDI ESTATAL: CONCEPTO Y POSIBLE CONTENIDO; 2. LA PREVENCIÓN ESPECIAL O EL IDEAL RESOCIALIZADOR COMO FUNDAMENTO Y FINALIDAD CONSTITUCIONAL DE LA PENA: CONCEPTO Y POSIBLE CONTENIDO; 3. A MODO DE CONCLUSIÓN; BIBLIOGRAFÍA.

\section{INTRODUCCIÓN: TESIS Y CONTENIDO DE LA DENOMINADA CONSTITUCIÓN PENAL Y SU VINCULACIÓN CON LOS}

\section{FINES DE LA PENA}

Como he señalado, ${ }^{1}$ a mi juicio, la idea de que la vinculación entre la Constitución Política de la República y el Código Penal no solo son de carácter lógico-formal y jerárquico, sino también de carácter material, sustancial o teleológicas y que, por ello, la Carta fundamental debe ser entendida como el marco valorativo de todo el sistema penal, constituye un paradigma. ${ }^{2}$ Este punto de partida permite distinguir en la moderna doctrina penal dos grandes enfoques desde los cuales se ha emprendido el análisis del rol de la constitución política respecto del sistema penal y su reforma: la orientación sistemática lógico-formal o dogmática-penal, y la orientación sustancial, material o teleológica. ${ }^{3}$ Orientaciones que se distinguen, entre otras cuestiones, por el rol que le asignan a la constitución política en el marco del sistema penal. ${ }^{4}$

Así, mientras para la orientación sistemática o dogmática-penal, el rol de la constitución es, básicamente, limitar el poder del Estado en materia penal y garantizar los derechos del individuo; esto es, construir principios capaces de restringir el siempre excesivo e insaciable ius puniendi estatal, y la relación entre la constitución y el sistema penal - si existe- es una relación formal-negativa. Para la orientación material, sustancial o teleológica, en cambio, el poder punitivo del Estado debe estar definido y fundado en la constitución, no solo en cuanto a sus fines, objetivos e instrumentos, sino, además, en cuanto a los postulados o principios

1 Al respecto, Mario Durán, “Constitución y legitimación teórica de la pena. Apuntes teleológicos sobre el rol de la Constitución en el sistema penal”, en Revista Política Criminal 11 (2011), pp. 142-162.

2 Al respecto, en detalle, cfr. Santiago Mir y Mirentxu Corcoy (dirs.), Constitución y sistema penal, Madrid-Barcelona, Marcial Pons, 2012.

3 En un sentido similar, Ignacio BERdugo et al., Lecciones de derecho penal. Parte general, 2 ed., Barcelona, Praxis, 1999, pp. 39 y ss.; Nicolás GARCíA RIVAS, El poder punitivo en el Estado democrático de derecho, Cuenca, U. de Castilla-La Mancha, 1996, p. 43. Sobre la relación entre el derecho constitucional y el derecho penal, desde la óptica dogmática-penal, cfr. Klaus Tiedemann, "Constitución y derecho penal”, en REDC 33 (1991), pp. 145-171. Para un análisis particular sobre la orientación sustancial o teleológica y su visión sobre las relaciones entre constitución-derecho penal-criminología y realidad social, cfr. Mario Durán, Introducción a la Ciencia jurídico-penal contemporánea, Santiago, Ediciones Jurídicas de Santiago, 1996.

4 En este sentido, cfr. Massimo Donin, "Un derecho penal fundado en la carta constitucional: razones y límites. La experiencia italiana”, en vv.AA. Responsa Iurisperitorum Digesta, vol. II, Salamanca, Ediciones Universidad, 2001, pp. 223 y ss. Para un análisis pormenorizado, cfr. Massimo Donini, Il volto attuale dell'illecito penale. La democracia penale tra differenziazione e sussidiarietà, Milán, Giuffrè, 2004, pp. 61 y ss. 
de su sistema de argumentación y aplicación, es decir, su faz legislativa y judicial. Más aún, para esta orientación material, los principios político-criminales rectores del sistema penal no son meros límites formales al ius puniendi, sino verdaderos fundamentos o principios constituyentes del mismo, esto es, estructuran un derecho penal constitucional, cuya función esencial es garantizar los valores, bienes y derechos que en dicho texto se establecen.

De esta forma, es en la propia constitución democrática donde deben encontrarse el cuadro de valores y la jerarquía de bienes a los que el legislador debe atenerse para elaborar los intereses dignos de tutela penal. Esto es, con referencia a la Constitución, en sus conexiones técnico-jurídicas y valorativas con el sistema penal es como se debe establecer el concepto y el método del derecho penal, el concepto de delito, el fin de las penas y el sentido de la dogmática y del sistema. ${ }^{5}$

Por ello, desde este enfoque sustancial, material o teleológico, la Constitución, más que un mero límite, es el fundamento de la pena y del derecho penal. Esto significa que, tanto la elección de la conducta por sancionar, las técnicas que se deben emplear, los bienes jurídicos por proteger o las sanciones penales por aplicar, entre otras cuestiones, no pueden ser decisiones entregadas al simple capricho del legislador de turno, sino que debe tratarse de decisiones fundamentadas directamente en las valoraciones, los principios, las reglas y las decisiones político-criminales — condiciones o requisitos - que establezca la respectiva norma constitucional en materia penal. ${ }^{6}$ En definitiva, todo esto implica que el estándar de legitimidad del derecho penal o, más en general, de la forma de ejercer el poder punitivo del Estado, proviene del marco valorativo que el respectivo modelo de Estado fija en la Constitución. ${ }^{7}$

5 En este sentido, cfr. Claus Roxin, Derecho penal. Parte general, t. I, Fundamentos. La estructura de la teoría del delito, Madrid, Tecnos, trad. y notas Diego-Manuel Luzón Peña, Miguel Díaz y García Conlledo, Javier de Vicente Remesal, 1997, pp. 55 y ss.; Franco BRicolA, "Teoria generale del reato", en Scritti di Diritto Penale, vol. I, t. I, Milán, Giuffrè, 1997, pp. 539 y ss.; Sergio Moccia, Il Diritto penale tra essere e valore. Funzione sistematica teleologica. Nápoles, ESI, 1992; Massimo DoninI, Teoria del reato. Una introduzione, Padova, Cedam, 1995; del mismo autor, "Dogmatica penale e política criminal a orientamento costituzionalistico. Conoscenza e controllo critico delle secelte di criminalizzazione", en Dei delitte e delle pene 3 (1998), pp. 37 y ss.; Luis Arroyo, "Fundamento y función del sistema penal: el programa de la Constitución”, en RJCLM 1 (1987), pp. 97 y ss. En detalle, cfr. Mario DuRÁn, "El planteamiento teleológico constitucional de la Escuela de Bologna y la obra de Franco Bricola como antecedentes históricos y metodológicos de la noción de derecho penal constitucional”, en Revista de Derecho, U. Católica del Norte, 20, 2 (2013), pp. 305-326.

6 Al respecto, cfr. Manuel Atienza, "Constitucionalismo y derecho penal”, en Santiago Mir y Mirentxu Corcoy (dirs.). Constitución y sistema penal, op. cit., pp. 19 y ss. Gema MARCilla, "Argumentación en el ámbito legislativo y prestigio de la ley penal”, en Santiago MrR y Mirentxu Corcoy (dirs.), Constitución y sistema penal, op. cit., pp. 67 y ss.; Luiz Regis PRADO, Bien jurídico-penal y Constitución, Lima, ARA, trad. Luis Álvarez Aranda, 2010; Eugenio Raúl ZAFFARONI, "El marco constitucional iushumanista del saber penal”, en En torno de la cuestión penal, Colección Maestros del Derecho Penal 18, Montevideo-Buenos Aires, B de F, 2005, pp. 121 y ss.

7 En este sentido, cfr. Francisco Muñoz Conde y Mercedes García ArÁn, Derecho penal. Parte general, Valencia, Tirant lo Blanch, 1994, p. 64. 
Es de esta forma, entonces, que la discusión sobre la justificación del castigo penal renace como nueva y genera, a mi juicio, a lo menos dos requerimientos. ${ }^{8}$ Por una parte, la necesidad de destacar la importancia que una constitución democrática tiene respecto de la fundamentación de los fines del derecho penal y, segundo, la necesidad de dar un contenido o función, a través de dicha constitución democrática, a la aplicación de la pena. Por ello, este marco político-criminal supone que, entre otras definiciones, ${ }^{9}$ tanto al momento de creación como al momento de determinarse judicialmente la pena, deberían tener vigencia efectiva todos y cada uno de los presupuestos y principios - formales y materiales- que inspiran el porqué y el para qué de la reacción punitiva. ${ }^{10}$ Esto es, una creación limitada de la ley penal y una aplicación prospectiva de la determinación judicial de la pena, que considere los principios político-criminales limitadores del ius puniendi estatal establecidos desde la propia constitución penal. ${ }^{11}$

De ahí que, aceptado este punto de partida, se hace necesario establecer criterios en virtud de los cuales tanto legisladores como operadores del sistema jurídicopenal puedan justificar - racionalmente- la creación de normas jurídico-penales y la aplicación de la pena al caso concreto. Ello, porque solo sobre la base de fines político-criminales claramente definidos desde la constitución democrática, cabe pronunciarse sobre qué hechos puede recaer la creación de tipos penales (cuándo y de qué forma técnica), sino también, en el caso concreto, al momento de la individualización judicial de la pena, cómo estos fines deben valorarse si hubiera lugar a ello. ${ }^{12}$ Esto es, bajo qué fines, principios y objetivos funcionales se debería, dirigir y aplicar las medidas o sanciones penales.

8 La importancia de esta discusión en nuestro país obedece a diversas razones históricas, jurídicopolíticas y, sobre todo, metodológicas, más aún en nuestro actual estado de desarrollo en otros ámbitos. Al respecto, por escapar a los objetivos de este trabajo, cfr. Mario DuRÁn, "El derecho penal del enemigo. Formulación y observaciones críticas en el contexto del debate sobre la modernización y expansión del derecho penal", en Manuel CANcio (ed.), Derecho penal del enemigo. El discurso penal de la exclusión, Buenos Aires, Montevideo, B de F, Madrid, Edisofer, 2006, pp. 725 y ss.; Mario Durán, "Justificación y legitimación político-criminal de la pena. Concepto, criterios y orientaciones en la actual jurisprudencia nacional”, en Política criminal 8 (2009), pp. 266-291; Mario DuRÁn, "Constitución y legitimación teórica de la pena. Apuntes teleológicos sobre el rol de la Constitución en el sistema penal", op. cit., pp. 142 y ss.; "Teorías absolutas de la pena: origen y fundamentos. Conceptos y críticas fundamentales a la teoría de la retribución moral de Immanuel Kant a propósito del neo-retribucionismo y del neo-proporcionalismo en el derecho penal actual”, en Revista de Filosofia 67 (2011), pp. 123 y ss.

9 Sobre la problemática previa a esta cuestión, cfr. Juan Bustos, "Política criminal y derecho penal", en Obras Completas. Control social y otros cambios, t. II, 2 ed., Santiago, Ediciones Jurídicas de Santiago, 2007, pp. 18 y ss.

10 Sobre el problema de la determinación judicial de la pena y la discrecionalidad, véase Luigi $\mathrm{FE}_{\mathrm{E}}$ RRAJOLI, Derecho y razón. Teoría del garantismo penal, Madrid, Trotta, trad. P. Andres, A. Ruiz, J. Bayón, J. Terradillos y R. Cantarero, 2000, pp. 402 y ss. En Chile sobre esta problemática, cfr. Carlos Künsemuller, "La judicialización de la ejecución penal", Derecho penal y política criminal (compilación de artículos), Santiago, Legal Publishing, 2012, pp. 635 y ss.

11 En este sentido, se señala que "cuando se decide cuánto castigo debe padecer el reo, es el momento en el que las cuestiones fundamentales sobre el por qué y para qué se le sanciona, han de descender de lo programático a la sentencia concreta". Gonzalo guinTERo, "Determinación de la pena y politica criminal”, en CPC 4 (1982), pp. 49 y ss.

$28812 \mathrm{Al}$ respecto, en detalle, Hans-Heinrich Jescheck, Tratado de derecho penal. Parte general, Granada, Comares, trad. José Luis Manzanares Samaniego, 1993, pp. 790 y ss.; Mario MAGARIÑos, "Hacia un criterio para la determinación judicial de la pena”, en AA.VV., Determinación judicial de la pena, 
En consecuencia, es justamente en este sentido donde el estudio del fin de la pena, establecido desde la Constitución, toma su real valor y alcance permitiendo, a mi juicio, ser analizado desde una doble perspectiva. Una, que podemos denominar de limitación material al ius puniendi estatal y otra, que podemos denominar teleológica, que, más bien, fundamentaría y justificaría la aplicación de la sanción penal.

De esta manera, y bajo este marco teórico, la propuesta que se presenta a continuación es analizar el rendimiento que en este sentido tendría el establecimiento de un fin preventivo especial o resocializador de la pena en la constitución. Para ello, se intentará conceptualizarlo y delimitar su contenido, tanto como límite al ius puniendi como al postulado de ser un fin teleológico de la pena. Esto es, presentar la prevención especial o resocialización del delincuente como un posible fundamento y limite constitucional de la pena.

\section{LA PREVENCIÓN ESPECIAL O EL IDEAL RESOCIALIZADOR COMO PRINCIPIO LIMITADOR DEL IUS PUNIENDI ESTATAL: CONCEPTO Y POSIBLE CONTENIDO}

En la actualidad, desde la primera perspectiva arriba enunciada, el denominado principio de resocialización, fruto del posmoderno ideal resocializador, se ha constituido y estructurado como un límite al ius puniendi estatal característico del modelo de Estado social y democrático de derecho, que tiende a consolidarse como un limite de orden material dirigido a restringir la creación o producción de normas penales. ${ }^{13}$

En este ámbito, al analizar la evolución del principio o ideal resocializador y su relación con la ejecución de la pena, especialmente con la pena privativa de libertad, ${ }^{14}$ se ha establecido que en el Estado liberal clásico la idea de resocialización no tenía ni tiene cabida puesto que la pena era la respuesta adecuada al delito como

Buenos Aires, Editores del Puerto, 1993, pp. 74 y ss. Claus Roxin, "La determinación de la pena a la luz de la teoría de los fines de la pena”, en Culpabilidad y prevención en el derecho penal, Madrid, Reus, trad. Francisco Muñoz Conde, 1981, pp. 46 y ss.; Patricia ZifFer, "Consideraciones acerca de la problemática de la individualización de la pena”, en AA.VV., Determinación judicial de la pena, op. cit., pp. 91 y ss.

13 Al respecto, cfr. Carlos Künsemuller, "Importancia dogmática y político-criminal de los principios limitadores del ius puniendi”, en Derecho penal y politica criminal, op. cit., pp. 197 y ss; Juan BusTOS, "Principios garantistas del derecho penal y del proceso penal", en Obras completas, t. II., op. cit. pp. 511 y ss.: Manuel de RIvacoBa, "Introducción al estudio de los principios cardinales del derecho penal”, en Revista Brasileira de Ciencias Crimináis n 32 (2000), pp. 39 y ss. ZafFaroni, Alagia, Slokar, Manual de derecho penal. Parte general, 2 ed., Buenos Aires, Ediar, 2006, pp. 29 y ss.

14 Al respecto, cfr. R.-P. CALLIEs, Theorie der Strafe im demokratischen und sozialen Rechtsstaat, Frankfurt am Main, 1974, pp. 18 y ss.; pp. 173 y 160, citado por Santiago Mir, Introducción a las bases del derecho penal, Barcelona, Bosch, 1975. p. 164. Para un breve análisis histórico de la perspectiva resocializadora, cfr. Jesús-María SiLvA, Aproximación al derecho penal contemporáneo, Barcelona, Bosch, 1992, pp. 26-33; José Miguel Zugaldía, Fundamentos de derecho penal. Parte general. Las teorías de la pena y de la ley penal, Granada, U. de Granada, 1990, pp. 203 y ss.; Ignacio Berdugo et al., Lecciones de derecho penal, op. cit., pp. 65-67. Sobre la evolución de la pena en relación con el modelo de Estado, en detalle, cfr. Juan Bustos y Hernán Hormázabal, "Pena y Estado", en Papers, Revista de Sociología 13 (1980), pp. 97 y ss. 
hecho, sin que la personalidad del sujeto pudiese verse implicada, ni siquiera a los efectos de tratamiento. En el Estado social, en cambio, al tener un signo intervencionista, se admite tomar en consideración al sujeto, en las medidas de seguridad y dentro del marco de la ejecución de la pena, pero, lamentablemente, ello se concibió al margen de la participación del sujeto, que fue considerado como mero objeto de la acción del Estado.

Por ello, el Estado democrático y social de derecho debe completar esta evolución concibiendo la participación del sujeto como base del contenido de la reacción penal. Así, para cumplir con este objetivo, el Estado democrático debe establecer una concepción resocializadora de la ejecución de la pena, en especial de la pena privativa de libertad, que tienda a crear — en el condenado- posibilidades reales de participación en los sistemas sociales, ofreciendo alternativas al comportamiento criminal.

De igual forma, para alcanzar la meta democrática, la concepción resocializadora de la ejecución de la pena no debería imponerse al condenado sin contar con su participación, sino que debería constituir el producto de un permanente diálogo entre el Estado y el condenado. El efecto, respecto del cumplimiento de la pena y su forma de ejecución, sería que este no estaría fijado de antemano, ciegamente, en la sentencia, sino que iria concretándose y modificándose por obra del mencionado diálogo. ${ }^{15}$

Así, desde esta perspectiva limitadora, la constitución penal y la determinación del deber resocializador para el sistema penal de un Estado democrático, implicaría directamente que este debe evitar la marginación social indebida de aquel sujeto condenado a una pena o sometido a una medida de seguridad e, indirecta y previamente, aquella marginación social y económica que posibilita el delito.

Por ello, este deber implica, directamente, no solo que se deben evitar - en lo posible - las penas o medidas que entrañen una separación de la sociedad, sino además que, cuando la privación de libertad sea inevitable, debe configurarse su ejecución de forma tal que evite - también en lo posible- sus efectos desocializadores, principalmente, fomentando cierta comunicación con el exterior y facilitando una adecuada reincorporación del recluso a la vida en libertad. ${ }^{16}$ También, y de manera indirecta, este deber se relaciona con el respeto de los derechos fundamentales del individuo, específicamente con el principio de humanidad o dignidad de la persona.

En este segundo sentido, el respeto al principio de la dignidad de la persona constituye el último y fundamental limite material a la actividad punitiva del Estado. Su importancia radica en que, sin su resguardo y existencia, ni el ideal resocializador,

15 En detalle, cfr. Mario DuRÁn, "Prevención especial e ideal resocializador. Concepto, evolución y vigencia en el marco de la legitimación y justificación de la pena”, op. cit., pp. 57 y ss.

16 En este sentido, cfr. Santiago Mir, Derecho penal. Parte general, 5 ed., Barcelona, Reppertor, 2000, p. 101. 
y menos la necesidad de la intervención penal o la protección de bienes jurídicos, tendrían sentido, con lo cual se socavarian todos los principios garantistas. ${ }^{17}$ El principio de humanidad o dignidad de la persona implica el reconocimiento a la autonomía ética de la persona y a su indemnidad personal. Esto es, que la persona es un fin en sí mismo por lo que jamás puede ser el medio para otro objetivo y que, por tanto, siempre el Estado está a su servicio, de lo que se concluye que la persona no puede ser considerada como un objeto que queda sometido a la exclusiva dirección del Estado. Cuestión fundamental a tener en consideración a la hora de justificar el castigo y limitar el ius puniendi estatal.

Asimismo, respecto de la indemnidad personal, el principio de humanidad o dignidad de la persona quiere expresar que ninguna intervención del Estado puede significar una afectación a la persona como tal, por lo que el Estado no puede incidir en la esencia de un derecho o impedir absolutamente su ejercicio. ${ }^{18}$

Así, en relación con la limitación al ius puniendi, el principio de humanidad o dignidad de la persona permite, como efectivamente ha ocurrido en las legislaciones penales más avanzadas, ${ }^{19}$ no solo excluir la pena de muerte, el presidio perpetuo y las penas corporales en general, las condiciones ilegitimas de ejecución de las penas, los tratos inhumanos o degradantes, las torturas y toda aquella amenaza o vulneración a la dignidad humana, sino también construir todo el sistema penal sobre la base del respeto a la persona como tal y sus derechos fundamentales. ${ }^{20}$

En este sentido, en el marco del análisis de la evolución de los principios limitadores del ius puniendi, se señala con acierto que si el Estado de derecho exige el sometimiento de la potestad punitiva al principio de legalidad y en el Estado social dicha potestad solo se legitima si sirve de eficaz y necesaria protección de la sociedad, un Estado que además pretenda ser democrático tiene que llenar el derecho penal de un contenido respetuoso de la noción del ciudadano como sujeto dotado de una serie de derechos derivados de su dignidad humana. Idea que, al pretender ahondar en el camino de un derecho penal realmente democrático, no solo de garantías formales - sin duda, indispensables- sino también al servicio efectivo de todos los ciudadanos, nos permite afirmar que el principio de humanidad

17 En este sentido, cfr. Juan Bustos, Manual de derecho penal español. Parte general, Barcelona, Ariel, 1984, p. 65.

18 Juan Bustos y Hernán HormazáBal, Lecciones de derecho penal, op. cit., p. 69.

19 El artículo 15 de la Constitución Española de 1978 establece que "todos tienen derecho a la vida y a la integridad física y moral. Sin que, en ningún caso, puedan ser sometidos a tortura ni a penas o tratos inhumanos o degradantes. Queda abolida la pena de muerte, salvo lo que puedan disponer las leyes penales militares para tiempos de guerra”. Al respecto, véase el análisis extensivo de la prohibición de penas inhumanas y degradantes, que incluye la interdicción de penas inocuizadoras y ejemplarizadoras, en José Miguel Zugaldía, Fundamentos de derecho penal, op. cit., pp. 196 y ss. Sobre el mismo mandato en la Constitución Italiana y su relación con la resocialización, cfr. Giovanni VASSALLI, "I principi generali del Diritto nell'esperienza penalistica”, en RIDPP (1991), pp. 699 y ss., esp. 728-730.

20 Para un desarrollo de esta idea, aplicada a la estructura del delito, a las garantías político-criminales y procesales, cfr. Klaus VolK, "Sistema penale e diritti dell'uomo", en Sergio Moccia (a cura di), Diritti dell'uomo e Sistema Penale, vol. I, Napoli-Roma, Edizioni Scientifiche Italiane, 2002, pp. 93 y ss. 
es el principio que en mayor medida caracteriza el origen y la evolución del contenido del sistema penal contemporáneo. ${ }^{21}$

Por ello, debe considerarse que también forman parte del principio de humanidad o de dignidad de la persona, los principios de exclusión de la responsabilidad objetiva -exigencia de dolo o culpa-, el de responsabilidad por el hecho o exclusión del derecho penal de autor ${ }^{22}$ y modelos restrictivos de derecho fundamentales como el denominado derecho penal del enemigo. ${ }^{23}$

Además, cabe derivar también del principio de humanidad la exclusión de toda intervención punitiva que pretenda incidir sobre el fuero interno de los individuos, en lugar de pretender de ellos la mera adecuación de la conducta externa. Ello, sobre todo, porque con la inclusión de estos principios, no solo queda de manifiesto la importancia que el principio de humanidad o de dignidad de la persona tiene en la configuración del concepto de culpabilidad, sino que expresa su importancia respecto del establecimiento de la prohibición de imponer sanciones penales a supuestos en que la realización del presupuesto de la misma es inevitable. ${ }^{24}$

Más aún, desde la perspectiva de los principios de la politica criminal, se señala que el principio de humanidad se ha convertido, sobre todo, en el pensamiento rector de la ejecución penal, vinculándose estrechamente con el ideal resocializador. Por ello, los efectos del mismo se deben expresar en el sentido de que todas las relaciones humanas que surjan del derecho penal -en su más amplio significado- deben ordenarse sobre la base de la solidaridad reciproca, de la responsabilidad social para con los reincidentes, de la libre disposición hacia la ayuda y la asistencia sociales, y de la decidida voluntad de recuperar a los delincuentes condenados. $^{25}$

Asimismo, las consecuencias que supone el principio de humanidad deben reflejarse también en el proceso penal, en la abolición de determinados tipos de pena, en la aplicación de salidas alternativas y en la ejecución sustitutiva de las penas privativas de libertad. ${ }^{26}$

21 En este sentido, cfr. Santiago Mir, Derecho penal, op. cit., p. 94.

22 Sobre el derecho penal del hecho como tendencia predominante en el derecho penal, las tendencias del derecho penal de autor en la Alemania nazi y las actuales influencias del derecho penal de autor, cfr. Claus Roxin, Derecho penal. Parte general, op. cit., pp. 176 y ss.; José Miguel ZugaldíA, Fundamentos de derecho penal, op. cit., pp. 212-214. Sobre este tema y la pena, cfr. Diego-Manuel LuZón, "Principio de igualdad. Derecho penal de hecho y prevención especial: equilibrio y tensiones”, en Adela Asúa (coord.), El pensamiento penal de Beccaria: su actualidad, Bilbao, U. de Deusto, 1990, pp. 67 y ss. Respecto a Chile, cfr. Carlos Künsemuller, "Praeter intentionem y principio de culpabilidad”, en Derecho penal y politica criminal, op. cit., pp. 292 y ss.

23 Al respecto, Mario DuRÁn, "El derecho penal del enemigo. Formulación y observaciones críticas en el contexto del debate sobre la modernización y expansión del derecho penal”, en Manuel CANCIO (ed. y coord.), Derecho penal del enemigo. El discurso penal de la exclusión, op. cit., pp. 725 y ss.

24 Al respecto, cfr. Jesús-María Silva, Aproximación al derecho penal contemporáneo, op. cit., p. 261.

25 Cfr. Hans-Heinrich Jescheck, Tratado de derecho penal. Parte general, op. cit., p. 23.

26 En este sentido, cfr. Francisco Muñoz Conde, Introducción al derecho penal, op. cit., p. 77. 
En cuanto al proceso penal, el principio de humanidad ha llevado -y debe llevar alli donde aún no se aplique - a la abolición de la tortura como medio de averiguación de la verdad y a la de cualquier otro medio que prive al acusado de la libre determinación de su voluntad, como el lavado de cerebro, el detector de mentiras, el suero de la verdad, etc. ${ }^{27}$ Asimismo, en relación con la pena de muerte, el principio de humanidad impone su abolición, dado que no sirve más que otras penas para proteger a la comunidad, ni permite ningún tipo de acción resocializadora sobre el delincuente, ni, desde luego, es necesaria para garantizar la paz social. ${ }^{28}$

Finalmente, respecto al tema de la ejecución de las penas privativas de libertad, no solo resulta claro que el principio de humanidad obliga a tratar con respeto al encarcelado y procurar su reinserción en la vida social, una vez que haya salido de la cárcel, ahorrándole, en todo caso, todo tipo de vejaciones y de sufrimientos. Además, el principio de humanidad implica que el padecimiento en que consiste la pena ha de ser el estrictamente imprescindible, debiéndose armonizar, por tanto, la dignidad de la persona y la potestad del Estado, por ejemplo, a través del aumento del uso - cuando sea posible- de los contactos del condenado con el exterior, así como la proscripción de las penas inútiles y el fortalecimiento de las medidas alternativas a las penas privativas de libertad o sustitutos penales. ${ }^{29}$ Ello, principalmente, porque la humanidad de la pena de prisión depende absolutamente de la modalidad de su ejecución. ${ }^{30}$

\section{LA PREVENCIÓN ESPECIAL O IDEAL RESOCIALIZADOR COMO FUNDAMENTO Y FINALIDAD CONSTITUCIONAL DE LA PENA: CONCEPTO Y POSIBLE CONTENIDO}

Como se ha señalado, entre otros, ${ }^{31}$ el derecho penal constitucional estaría integrado por aquellos preceptos constitucionales sobre mandatos, prohibiciones y

27 Al respecto, entre otros, cfr. Cesare Beccaria, De los delitos y de las penas, Madrid, Alianza, trad. Juan Antonio de las Casas; Introducción, apéndice y notas de Juan Antonio Delval, 1998, pp. 58 y ss.; Francisco Tomás y Valiente, La tortura en España, 2 ed., Barcelona, Ariel, 1994; El derecho penal de la monarquía absoluta (siglos XVI, XVII y XVIII), 2 ed., Madrid, Tecnos, 1998; Michael FoucAult, Vigilar y castigar, 12 ed., Madrid, Siglo XXI, trad. Aurelio Garzón del Camino, 2000, pp. 11 y ss.

28 En este sentido, cfr. Ángel Torio López, "La pena de muerte. Problemática histórica y contemporánea”, en Adela Asúa (coord.), El pensamiento penal de Beccaria: su actualidad, op. cit., pp. 95 y ss. Sobre la historia y los argumentos en pro y en contra de la pena de muerte, con análisis de derecho comparado, cfr. Carlos GARCíA VAldÉs, Teoría de la pena. 3 ed., Madrid, Tecnos, 1985, pp. 25-65.

29 En este sentido, entre otros, cfr. Juan CóRDoBa, "La pena y sus fines en la Constitución española de 1978”, en Papers 13 (1980), pp. 129 y ss., esp. p. 139; Ángel ToRIo López, "La prohibición constitucional de las penas y tratos inhumanos o degradantes”, en Poder Judicial 4 (1986), pp. 69 y ss.; Jesús-María silva, Aproximación al derecho penal contemporáneo, op. cit., p. 264; Carmen LamarCA, "Régimen penitenciario y derechos fundamentales", en EPC XVI (1993), p. 220; José Miguel ZUGALDÍA, Fundamentos de derecho penal, op. cit., pp. 196 y ss. Alessandro BARATTA, "Cárcel y Estado social. Por un concepto de 'reintegración social' del condenado”, en Enrique Olivas, Problemas de legitimación en el Estado social, Madrid, Trotta, 1991, pp. 137 y ss.

30 En este sentido, cfr. Vicenta cervelló, Derecho penitenciario, Valencia, Tirant lo Blanch, 2001, p. 47.

31 Esto es, la proscripción de la tortura, de las penas y tratos inhumanos y degradantes, y la abolición de la pena de muerte; la consagración de las garantías de la libertad personal frente a la privación de la libertad, con cláusulas expresas sobre la detención preventiva y la prisión provisional; la formulación de un catálogo de garantías que integran el derecho a la tutela judicial efectiva y 
regulaciones que afectan directamente al derecho penal, incluyendo entre ellos la consagración expresa de un fin de la pena que, junto con la prevención del delito, en el modelo de Estado social y democrático está generalmente constituido por el principio de resocialización. ${ }^{32}$

De acuerdo con los objetivos de este trabajo, ${ }^{33}$ se puede señalar que fundamentar la pena en la denominada prevención especial o individual del delito, consiste primero que nada en concebir la pena como un medio, como un mecanismo o instrumento, que solo se justifica en la medida que se emplee para la lucha contra el delito y su proliferación en la sociedad. Al mismo tiempo, significa también diferenciarse de las ideas de la prevención general, tanto positiva como negativa, en cuanto a que la prevención especial o individual no está dirigida a la generalidad o conjunto de los ciudadanos, sino al autor del delito, al delincuente, al sujeto individual que soporta la carga o mal que constituye la pena, en este caso, específica e individualizada. Por ello, debe entenderse claramente que desde esta perspectiva, a diferencia de la prevención general que aspira a prevenir el delito en relación con la totalidad de los ciudadanos, la prevención especial o individual se dirige al propio reo. ${ }^{34}$ Por lo mismo, la prevención especial no puede operar, como la general, en el momento de la conminación legal, sino en los de imposición y ejecución de la pena. ${ }^{35}$

Por estas razones, en sintesis, la teoria de la prevención especial o individual viene a significar la búsqueda de una solución contra del delito que aspira a que el delincuente, que ya ha sufrido la pena, sea apartado "de nuevos yerros y educado para que se adapte a las pautas sociales de la colectividad”. ${ }^{36}$ Afirmándose, con razón, que la teoría de la prevención especial, "no quiere retribuir el hecho pasado, sino que ve la justificación de la pena en que debe prevenir nuevos delitos del autor" ${ }^{37}$

En este marco fundamentador y teleológico, y partiendo de la base de que la pena es, en esencia, pura coacción ya que "se dirige contra la voluntad del autor del delito, cuyos bienes jurídicos lesiona o destruye, pues de ellos se ha personificado su voluntad", ya von Liszt propuso la distinción de una doble naturaleza en

a un proceso con todas las garantías, con expresa consagración de la presunción de inocencia; la proclamación del principio de legalidad y de irretroactividad en materia sancionatoria, y de la proscripción de la privación de libertad en el ámbito del poder sancionador de la Administración. En detalle, cfr. Mario Durán, “Constitución y legitimación teórica de la pena. Apuntes teleológicos sobre el rol de la Constitución en el sistema penal”, op. cit., pp. 150 y ss.

32 En este sentido, el artículo 25.2 de la Constitución Española señala: "2. Las penas privativas de libertad y las medidas de seguridad estarán orientadas hacia la reeducación y reinserción social y no podrán consistir en trabajos forzados".

33 Respecto del origen y la evolución de la prevención especial, cfr. Mario DuRán, "Prevención especial e ideal resocializador. Concepto, evolución y vigencia en el marco de la legitimación y justificación de la pena”, op. cit., pp. 57 y ss.

34 Cfr. Hans-Heinrich Jescheck, Tratado de derecho penal. Parte general, op. cit., p. 60.

$\begin{array}{lll}294 & 35 & \text { Cfr. Santiago Mir, Derecho penal. Parte general, op. cit., p. } 53 . \\ & 36 & \text { Hans-Heinrich JEScHECK, Tratado de derecho penal. Parte general, op. cit., p. } 60 .\end{array}$

37 Claus Roxin, "Sentido y limites de la pena estatal", en Problemas básicos del Derecho penal, Madrid, Reus, trad. y notas por Diego-Manuel Luzón Peña, 1976, p. 15. 
la pena; ${ }^{38}$ la motivación o coacción indirecta, mediata o psicológica y la fuerza o coacción directa, inmediata y mecánica. ${ }^{39}$ Con ello, y consecuente con los efectos de la pena propuestos, von Liszt esboza el contenido para el nuevo sistema de penas dirigido, no contra del delito, sino contra el delincuente. ${ }^{40}$

Para tal efecto, von Liszt distingue - las hoy ya clásicas - tres categorias de delincuentes y penas; ${ }^{41}$ la corrección del delincuente capaz de corregirse y necesitado de corrección; ${ }^{42}$ la intimidación del delincuente que no requiere corrección, ${ }^{43}$ y la inocuización del delincuente incapaz de corrección. ${ }^{44}$

En cuanto a las modalidades que la prevención especial puede asumir, ya Antón Oneca, al desarrollar las ideas de von Liszt en España, señaló que, "se impone, pues, dividir el fin de readaptación a la vida legal, corrección en sentido amplio,

38 Cfr. Franz von Liszt, La idea del fin en el derecho penal. Programa de la Universidad de Marburgo, 1882, Granada, Comares, 1995, pp. 80 y ss.

39 La pena como motivación proporciona al delincuente los motivos que a él le faltan y que son los idóneos para disuadirlo impidiendo la comisión del delito, e incrementa y fortalece los motivos ya existentes. Aquí la pena aparece como un mecanismo de "acomodación artificial" del delincuente a la sociedad, lo que se puede obtener, a su vez, de dos formas; mediante la corrección, es decir, a través de la implantación y el fortalecimiento de motivos sociales y altruistas, o por medio de la intimidación, esto es, "a través de la implantación y fortalecimiento de motivos egoístas" pero coincidentes en los efectos con los motivos anteriores. La pena como fuerza constituye el secuestro del autor del delito, la inocuización transitoria o permanente, la expulsión de la sociedad o, dentro de esta, su internamiento. Es, "una selección artificial de los individuos socialmente inidóneos". Cfr. Franz von Liszt, La idea del fin en el derecho penal, op. cit., pp. 80-83.

40 Para von Liszt, la corrección, la intimidación y la inocuización son los efectos inmediatos de la pena, que se encuentran inmersos en las fuerzas del instinto y por medio de los cuales se consigue la protección de los bienes jurídicos. Si la corrección, la intimidación y la inocuización son de hecho las consecuencias esenciales y posibles de la pena, y por tanto, a la vez, las formas posibles de protección de bienes jurídicos a través de una pena, cada una de estas tres formas de pena tendría que corresponder a tres categorias de delincuentes. Por tanto, la pena no se dirige contra el delito, sino contra los delincuentes. Cfr. Franz von Liszt, La idea del fin en el derecho penal, op. cit., p. 81.

41 Ibid., pp. 83 y ss.

42 Para von Liszt, estos son sujetos propensos al delito que pueden ser salvados para la sociedad a través de una educación severa y prolongada en pequeñas prisiones con penas privativas de libertad no inferiores a un año ni superiores a cinco, "puesto que las penas de corta duración [...] no consiguen más que fracasar creando un futuro delincuente habitual". Cfr. Franz von LiszT, La idea del fin en el derecho penal, op. cit., pp. 88-89.

43 Según von Liszt, estos son delincuentes ocasionales para quienes el delito es un error y hay poco peligro de repetición. Aquí no se aplica la corrección sistemática, la pena tiene como fin reestablecer la autoridad de la ley infringida, debe servir como intimidación, advertencia contundente o escarmiento para sus instintos egoístas, abarcando todos los delitos y las faltas. Cfr. Franz voN LiszT, La idea del fin en el derecho penal, op. cit., p. 90.

44 Para von Liszt, estos individuos forman "el ejército de los enemigos del orden social, en cuyo estado mayor figura el delincuente habitual, y que poseen, además, la característica de ser, según las estadísticas, delincuentes reincidentes y, por tanto, incorregibles". Aquí es poco lo que la sociedad puede hacer, resultando absurda la pretensión -propia del sistema retributivo de la pena- de internarlos en celdas de prisión con altos costos económicos, solo para que expíen su culpa y, al cabo de algunos años, se les deje en libertad para luego ser internados otra vez. Por ello, a la tercera condena por delito en contra de la propiedad o por delitos sexuales, se plantea la pena de reclusión por tiempo indeterminado, en régimen de comunidad y en un presidio de carácter disciplinario o de trabajos forzados. Con un régimen de esclavitud penal que obligue a trabajar y donde el castigo corporal sea pena disciplinaria, junto al aislamiento o incomunicación, el arresto en oscuridad y el ayuno estricto. Cfr. Franz von LiszT, La idea del fin en el derecho penal, op. cit., pp. 84-88. 
en dos: intimidación individual o escarmiento, y la 'mejora', enmienda o corrección en sentido estricto". ${ }^{45}$

Modernamente, se ha expresado que en la prevención especial o individual se pueden distinguir "los aspectos de la advertencia o intimidación individual, la corrección o enmienda del delincuente o al menos su readaptación social, y la separación o inocuización, cuando se trate de delincuentes incorregibles o de corrección prácticamente imposible". ${ }^{46}$

En esta misma línea en las últimas décadas, desde una perspectiva político-criminal y bajo la influencia de Franz von Liszt, el Proyecto Alternativo de Código Penal Alemán de 1966 (Alternativ Entwurf) ${ }^{47}$ planteó, junto con la desconexión de la idea de la retribución, la prioridad de la prevención especial sobre la prevención general. Esto es, no solo postula la sustitución de la pena retributiva por la pena con arreglo a fin, sino, sobre todo, subordinar, de entre los dos fines de la pena que quedan, la prevención general a la prevención especial. Por eso, de los puntos de vista decisivos para la medición de la pena, este Proyecto menciona la "reincorporación del sujeto" expresamente antes que la "protección de bienes jurídicos". ${ }^{48}$

De ello Roxin deduce que, en la esfera de la criminalidad mediana y pequeña, es decir, en la mayor parte de los delitos, la prevención especial reclama la prioridad absoluta, pues excluye la ejecución de una pena privativa de libertad. Por esta razón, en el Proyecto Alternativo, solo respecto de los delitos capitales, especialmente en los delitos contra la vida, prevalecen, de modo delimitado, las necesidades de prevención general en el sector de la pena privativa de libertad. Pero, por lo mismo, en la ejecución de la pena solo se debe perseguir el fin de resocialización, lo que explica tanto la supresión de la pena de reclusión y de sus consecuencias deshonrosas, en determinadas figuras. ${ }^{49}$

Así, el Proyecto Alternativo no solo aclara con toda la amplitud posible la relación que ambos fines de la pena guardan entre sí, sino que también sigue al milimetro la sugerencia de von Liszt al legislador para que se decida "a partir de una de

45 José AnTón OnEcA, La prevención general y la prevención especial en la teoría de la pena. Discurso leído en la apertura del curso académico de 1944 a 1945 U. de Salamanca, Salamanca, Ed. Cervantes, 1944, p. 71 . El autor realiza un excelente análisis acerca del sentido, el origen y los efectos de la corrección, del escarmiento y de la inocuización del delincuente; pp. 72 y ss., pp. 76 y ss., y pp. 81 y ss., Resp.

46 Cfr. José Cerezo, Curso de derecho penal español. Parte general I. Introducción teoría del delito/ 1, 3 ed., Madrid, Tecnos, 1992, p. 22.

47 En detalle, Mario Durán, Introducción a la Ciencia jurídico-penal contemporánea, Santiago, Ediciones jurídicas de Santiago, 1996, pp. 211 y ss.

48 Según Roxin, del propio contexto legal se desprenden directrices concretas para ponderar ambos fines de la pena, si en el caso concreto son divergentes. Por ejemplo, la concesión de beneficios -condena condicional, libertad condicional, sustitución de pena privativa de libertad por pena pecuniaria, admisión del trabajo de utilidad pública y amonestación con reserva de pena- generalmente depende en forma exclusiva de un juicio de prevención especial, esto es, de si el sujeto volverá a delinquir o no en el futuro, por lo que, en estos casos, nunca puede decidir el punto de vista preventivo general. Cfr. Claus Roxin, "Franz von Liszt y la concepción político-criminal del proyecto alternativo", op. cit., pp. 42-43.

Ibid., p. 43. 
las dos ideas fundamentales, pero no llevándola hasta sus últimas implicaciones, sino dando cuenta también de las consecuencias que se desprenden de la otra idea fundamental". ${ }^{50}$

Por ello, se ha indicado que, abstractamente, la prevención especial "puede tener dos vias diferentes: por medio de la coacción física, que debe impedir exteriormente que el autor cometa nuevos delitos, o mediante la remoción de la disposición que lo conduce a la delincuencia". ${ }^{51}$

Es en este sentido entonces en que debe entenderse la propuesta de Zugaldia en cuanto a subdividir la prevención especial en dos modalidades; positiva y negativa, atendiendo, en términos similares a los planteados por von Liszt, a la función o fin que la pena pretende cumplir respecto del individuo delincuente. ${ }^{52}$ Así, la prevención especial positiva sería aquella a través de la cual se tiende a evitar la recaída del autor en el delito haciendo que la pena desarrolle respecto de él una función admonitoria o resocializadora. La admonitoria o amonestante, cumpliría con la finalidad de evitar la reiteración del delito por parte del sujeto, dándole a la pena una función de aviso, advertencia o llamada de atención al delincuente para que se abstenga de delinquir en el futuro. ${ }^{53}$ Con la función resocializadora de la pena se pretende, mediante un tratamiento individualizado científicamente, hacer del autor una persona con la intención y la capacidad de vivir respetando la ley penal, así como de subvenir a sus necesidades. ${ }^{54}$

En la prevención especial negativa, en cambio, se trata de evitar que el autor exprese su mayor o menor peligrosidad en sus relaciones sociales. Por ello, debe utilizarse aquí la pena inocuizadora o de eliminación, que produce sus efectos especialmente respecto de aquellos delincuentes que no necesitan ser resocializados, los accidentales o coyunturales, y sobre aquellos que no pueden ser resocializados, como los habituales y los delincuentes por convicción. Pena inocuizadora que, a su vez, puede ser temporal o definitiva. ${ }^{55}$

50 Franz von Liszt, Lehrbuch des Deutschen Strafrechts, op. cit., p. 24, citado por Claus Roxin, "Franz von Liszt y la concepción político criminal del proyecto Alternativo”, op. cit., p. 43.

51 Cfr. Günther Stratenwerth, Derecho penal. Parte general, I. El hecho punible. Madrid, Edersa, Instituto de Criminología de la U. Complutense de Madrid, trad. de la 2 ed. alemana (1976) de G. Romero, 1982, p. 14.

52 José Miguel Zugaldía, Fundamentos de Derecho Penal. PG. Las teorías de la pena y de la ley penal, op. cit., pp. 63 y ss.

53 La pena admonitoria jugaría un papel muy importante respecto a delincuentes primarios y escasamente peligrosos, por lo que, normalmente, se conseguirian sus resultados a través de penas no privativas de libertad, multas o con penas privativas de libertad de corta duración. Cfr. José Miguel Zugaldía, Fundamentos de derecho penal. PG. Las teorías de la pena y de la ley penal, op. cit., p. 65.

54 José Miguel Zugaldía, Fundamentos de derecho penal. PG. Las teorias de la pena y de la ley penal, op. cit., p. 66. Tanto la Ley Orgánica General penitenciaria, en su artículo 59, como la CE de 1978, en su artículo $25 n^{\circ}$ 2, señalan expresamente este principio. Esto significa que, si se llega a la ejecución de una pena privativa de libertad, su cumplimiento ha de estar presidido por la idea de la resocialización, "fortaleciendo con su formación escolar, profesional y corporal el sentido de responsabilidad del recluso y procurando su colaboración activa en la vida del establecimiento". Cfr. Hans-Heinrich Jescheck, Tratado de derecho penal. Parte general, op. cit., p. 60.

55 Es temporal, cuando a través de ella "se procura apartar al autor durante un determinado periodo de tiempo [...] de la vida social [...] o de la fuente de peligro que le ha llevado a cometer el hecho 
En la actualidad, y como una manera de afrontar las importantes críticas frente a sus terribles e históricos excesos y manipulaciones politicas, ${ }^{56}$ se pretende limitar a ciertos presupuestos de aplicación el ideal resocializador y la teoría de la prevención especial. Esto es, que aun siendo el preferente no es el único fin de la pena, ya que la retención y custodia en la prisión, así como el resto de fines punitivos, también tienen su presencia; ${ }^{57}$ no es un derecho subjetivo, sino un principio programático que ha de orientar toda la politica penal y penitenciaria ${ }^{58}$ su alcance no debe limitarse solo a las penas privativas de libertad, sino también al resto de penas, y no ha de limitarse exclusivamente al momento de la ejecución, sino también a los de previsión legal y de determinación judicial de la pena. ${ }^{59}$

Por estas razones, se puede señalar que lo que ha evolucionado en cuanto al contenido del fundamento preventivo especial de la pena es el sentido de la referencia al fin resocializador, que ahora se entiende en términos claramente garantísticos. Esto es, no como imposición de un determinado esquema de valores u orden social, sino como la creación de las bases para la autorrealización o autodesarrollo libre del individuo o, al menos, como la remoción de las condiciones que impidan que el sujeto vea empeorado, a consecuencia de la intervención penal, su estado de socialización. Finalidad que, en el marco de la constitución penal, debe ser un mandato al que el derecho penal debe tender. ${ }^{60}$

La humanización de la ejecución penal, además de moverse en el ámbito de los derechos humanos del recluso, supone un apoyo indirecto al propio mantenimiento del orden social o la seguridad del Estado, ya que lo que realmente atenta contra la seguridad estatal y el orden social es, precisamente, la deshumanización e indignidad que se refleja en la masificación y las ineficientes condiciones de salubridad o higiene de las cárceles. Razón por la que, como señalé arriba, la resocialización debe enlazarse con el principio de humanidad y dignidad, en el sentido de que debe ser entendida como el esfuerzo en suprimir o, cuanto menos, atenuar la

delictivo". Es definitiva, cuando a través de ella "se procura -para anular todo vestigio de peligrosidad- destruir la persona del autor (total o parcialmente) o segregarlo del grupo social de forma virtualmente indefinida". Ejemplo de la pena destructiva es la pena de muerte, de la destrucción parcial de la persona, las penas contenidas en el lema "contra violación castración" y de la pena segregativa, las privativas de libertad de larga duración y las de reclusión perpetua. Cfr. José Miguel Zugaldía, Fundamentos de derecho penal. PG. Las teorías de la pena y de la ley penal, op. cit., pp. 66-67.

56 Respecto de las críticas a la prevención especial, cfr. Mario Durán, "Prevención especial e ideal resocializador. Concepto, evolución y vigencia en el marco de la legitimación y justificación de la pena”, op. cit., pp. 57 y ss.

57 Por ello, los Tribunales de Justicia españoles han señalado que la pena debe cumplirse aunque el reo esté reinsertado, al igual que la pena corta de prisión, pese a sus efectos desocializadores. Cfr. Auto TC Español 486/1985, de 10 de julio; STS Español 120/2000, de 10 de mayo y STS 55/1996, de 28 de marzo.

58 En este sentido se han pronunciado los tribunales en España: STS 1/1987, de 21 de enero; STS 28/1988, de 23 de febrero y STS 2/1997, de 13 de enero.

59 En este sentido, cfr. Mercedes GARCİA, Fundamento y aplicación de penas y medidas de seguridad en el código penal de 1995, Navarra, Aranzadi, 1997, p. 34.

60 En este sentido, entre otros, Luis ARroyo, "Fundamento y función del sistema penal: el programa de la Constitución”, en RJCLM 1 (1987), pp. 97-112, esp. p. 107. Antes ya Zipf planteaba el objeto, las posibilidades y el contenido de este tipo de prevención, cfr. Heinz ZIPF, Introducción a la política criminal, Jaén, Edersa, trad. Miguel Izquierdo Masías-Picavea, 1979, pp. 157 y ss. 
nocividad de la prisión. ${ }^{61}$ Más aún, el moderno contenido del principio de resocialización exige la adopción de medidas que van más allá de la ejecución de la pena, por ejemplo, el término del sistema de antecedentes penales y otros que impliquen efectos estigmatizantes y discriminadores. ${ }^{62}$

En este marco, a mi juicio, muchos de los problemas de prevención de la criminalidad - en general - y de la imposibilidad práctica de efectuar una real resocialización de los delincuentes en los países en vías de desarrollo, tenderían a solucionarse si existiese en ellos un acceso más democrático a los servicios sociales básicos — salud, educación y vivienda - así como una real justicia social —redistribución de los ingresos-que posibiliten el acceso a los bienes y servicios de consumo, como demuestra la situación, en estos aspectos, de los países que gozan de un Estado social y democrático de derecho efectivo. ${ }^{63}$

Por ello, la idea de prevención del delito establecida en la constitución penal de un verdadero Estado social y democrático de derecho, que ve el crimen como un doloroso "problema social" - interpersonal y comunitario- de la comunidad, que nace en la comunidad y ha de resolverse por esta, debe entenderse distinguiendo entre la prevención primaria, la secundaria y la terciaria, en atención a la mayor o menor relevancia etiológica de los respectivos programas; a los destinatarios a los que se dirige; a los instrumentos y mecanismos que utilizan; y a los ámbitos de los mismos y los fines perseguidos. ${ }^{64}$

Esto es, la prevención primaria se debe orientar a las causas mismas, a la raíz del conflicto criminal, para neutralizar este antes de que el propio problema se manifieste. Trata de crear los presupuestos necesarios o de resolver las situaciones carenciales criminógenas, procurando una socialización provechosa acorde con los objetivos sociales. Educación y socialización, vivienda, trabajo, bienestar social y calidad de vida son ámbitos esenciales para la prevención primaria, que opera siempre a mediano y largo plazo, y se dirige a todos los ciudadanos. Las exigencias de prevención primaria suelen atenderse a través de estrategias de politica cultural, económica y social, cuyo objetivo último es dotar a los ciudadanos de capacidad social para superar de forma productiva eventuales conflictos.

61 En este sentido, cfr. Vicenta Cervelló, Derecho penitenciario, op. cit., pp. 49-50.

62 Ignacio BERDUGo et al., Lecciones de derecho penal, op. cit., p. 67.

63 Ya von Liszt señalaba que la mejor política criminal es una buena politica social. Como bien se señala, existen medios tanto o más eficaces que la pena y que resultan más favorables para el ciudadano; en primerísimo lugar, una política social dirigida a disminuir las diferencias sociales existentes y que vaya modificando el sistema social en términos que aumente su poder de convicción y haga más atractiva la participación en él en lugar de dar motivos con su mal ejemplo para la desviación. Así, Santiago Mir, Introducción a las bases del derecho penal, op. cit., pp. 125 y ss.; "Problemática de la pena y seguridad ciudadana", en El derecho penal en el Estado social y democrático de derecho, Barcelona, Ariel, 1994, p. 126. Sobre las políticas sociales como propuestas de la política criminal, cfr. Laura zúÑIGA, Política criminal, Madrid, Colex, 2001, pp. 206 y ss.

64 En detalle, Antonio GARCíA-PABLos, Tratado de criminología, 3 ed. actualizada, corregida y aumentada, Valencia, Tirant lo Blanch, 2003, pp. 983 y ss. 
Etiológicamente, la prevención secundaria actúa más tarde, cuando el conflicto criminal se exterioriza. Opera a corto y medio plazo y se orienta selectivamente a concretos o particulares sectores de la sociedad, esto es, a aquellos grupos y subgrupos que exhiben mayor riesgo de padecer o protagonizar el problema criminal. Esta prevención se plasma en la política legislativa penal y en la acción policial, y está fuertemente influenciada por los intereses de la prevención general.

Por último, la prevención terciaria, cuyo destinatario es la población reclusa o penada, tiene por objetivo esencial evitar la reincidencia y, de las tres modalidades, es la de más acusado carácter punitivo. Por ello, los programas "rehabilitadores" o "resocializadores" en que se concreta (muy alejados etiológica, criminológica y espacialmente de las raíces últimas del problema criminal), se llevan a cabo en el propio ámbito penitenciario. ${ }^{65}$

Así, las bases de una política criminal democrática de prevención del delito, en el marco del Estado social y democrático de derecho, ${ }^{66}$ estarian dadas, en primer lugar, por la convicción de que el objetivo último de una eficaz política de prevención no es erradicar el crimen sino controlarlo razonablemente. Por ello, en este marco, cobra una importante relevancia el problema de los medios o instrumentos utilizados así como los costos sociales de la prevención del crimen, pues el control exitoso del mismo no justifica el empleo de cualquier programa ni legitima el elevado costo social de determinadas intervenciones.

De esta forma, prevenir el delito es más que disuadir u obstaculizar su comisión, intimidando al infractor potencial o indeciso, es intervenir en la etiología del problema criminal, neutralizando sus causas ya que deben atacarse estas y no sus sintomas o manifestaciones. Por ello, la efectividad de los programas de prevención debe plantearse a mediano y largo plazo, pues su eficacia es mayor en cuanto más directamente ataque las causas del conflicto que el delito exterioriza, esto es, los programas de prevención primaria son más útiles que los de prevención secundaria y estos más que los de la prevención terciaria. ${ }^{67}$

Por lo mismo, la prevención democrática del delito implica prestaciones positivas, aportaciones y esfuerzos solidarios que neutralicen situaciones carenciales, conflictos, desequilibrios o necesidades básicas. Solo reestructurando la convivencia social, redefiniendo positivamente la relación entre los miembros del sistema social y de estos con el sistema se pueden lograr avances en la prevención del delito. Sin perjuicio de establecer que, no obstante también se evita el delito previniendo la reincidencia, es mejor "producir" o "generar" menos criminalidad.

65 Al respecto, en detalle, cfr. Francisco Álvarez, "La reeducación y reinserción social en el momento de la conminación”, en Gonzalo Guintero y Fermín Morales (coords.), El nuevo derecho penal español. Estudios penales en memoria del profesor José Manuel Valle Muñiz, Navarra, Aranzadi, 2001, pp. $25 \mathrm{y}$ ss.

30066 En este sentido, cfr. Antonio GARCíA-PABLos, Tratado de criminología, op. cit., pp. 1066-1067.

67 En este sentido, vinculándolo críticamente al funcionalismo, cfr. Winfried Hassemer, "Prevención en el derecho penal”, Juan Bustos (dir.), Prevención y teoría de la pena. Santiago, Editorial Jurídica Cono Sur, 1995, pp. 93 y ss, esp. p. 111. 


\section{A MODO DE CONCLUSIÓN}

El presente trabajo pretende mostrar la existencia, en toda sociedad democrática, de profundas conexiones entre la denominada constitución penal y la necesaria justificación teórica del castigo penal.

Desde esta perspectiva, y luego de analizar el fundamento constitucional del derecho penal democrático, desde una visión política-criminal y en perspectiva constitucional, se ha intentado describir el doble rol que puede jugar la teoria de la prevención especial y el propio ideario resocializador en este contexto. Esto es, como límite material al ius puniendi estatal y como fundamentación teleológica o funcional de la aplicación de la sanción penal.

De lo expuesto se puede concluir, en primer lugar, que en contextos donde se plantea la necesidad de un nuevo orden constitucional - con un nuevo sistema de valores y principios realmente democráticos-, es necesario plantear también un cambio real y efectivo en el sistema penal y sus fines y objetivos. Principalmente, a través de la adopción de dichos valores y principios, y de la aplicación de los nuevos fines, objetivos e instrumentos que implica la nueva estructura democrática del Estado.

En segundo lugar, se puede señalar que, desde una óptica sustancial o teleológica, el rol del ideario resocializador y de las teorías de la prevención resulta plenamente vigente para darle contenido a dichos fines a través de los valores, objetivos e instrumentos que estos postulan y que han tratado de desarrollarse en este texto.

En tercer lugar, además, se puede plantear que, a partir de los conceptos, la evolución y el contenido arriba desarrollado, el rol de la teoría de la prevención especial y el ideario resocializador se cumple, tanto desde la perspectiva de límite material al ius puniendi estatal como desde la perspectiva de constituir un fundamento teleológico o funcional de la aplicación de la sanción penal.

De esta forma, a mi juicio, junto con destacar la importancia que una constitución democrática tiene respecto de la fundamentación del derecho penal y su posible contenido, queda al menos someramente esbozado el rol que este ideal puede cumplir para un sistema jurídico-penal orientado a prevenir el delito y resocializar al delincuente.

\section{BIBLIOGRAFÍA}

Álvarez, Francisco, "La reeducación y reinserción social en el momento de la conminación”, en Gonzalo Quintero y Fermín Morales (coords.), El nuevo derecho penal español. Estudios penales en memoria del profesor José Manuel Valle Muñiz, Navarra, Aranzadi, 2001, pp. 25 y ss. 
AnTón OnECA, José, La prevención general y la prevención especial en la teoría de la pena. Discurso leído en la apertura del curso académico de 1944 a 1945. U. de Salamanca, Salamanca, Ed. Cervantes, 1944.

ARroyo, Luis, "Fundamento y función del sistema penal: el programa de la Constitución”, en RJCLM 1 (1987), pp. 97 y ss.

Atienza, Manuel, “Constitucionalismo y derecho penal”, en Santiago Mir y Mirentxu Corcoy (dirs.), Constitución y sistema penal, Madrid-Barcelona, Marcial Pons, 2012, pp. 19 y ss.

Baratta, Alessandro, "Cárcel y Estado social. Por un concepto de 'reintegración social' del condenado", en Enrique olivas, Problemas de legitimación en el Estado social, Madrid, Trotta, 1991, pp. 137 y ss.

Beccaria, Cesare, De los delitos y de las penas. Con el comentario de Voltaire, Madrid, Alianza, trad. Juan Antonio de las Casas, introducción, apéndice y notas de Juan Antonio Delval, 1998.

Berdugo, Ignacio et al., Lecciones de derecho penal. Parte general, 2 ed., Barcelona, Praxis, 1999.

BRICola, Franco, "Teoria generale del reato", en Scritti di Diritto Penale, vol. I, t., I. Milán, Giuffrè, 1997, pp. 539 y ss.

Bustos, Juan, Manual de derecho penal español. Parte general, Barcelona, Ariel, 1984.

Bustos, Juan, "Política criminal y derecho penal", en , Obras completas. Control social y otros cambios, t. II, 2 ed., Santiago, Ediciones Jurídicas de Santiago, 2007, pp. 18 y ss.

Bustos, Juan, "Principios garantistas del derecho penal y del proceso penal”, en Obras completas, t. II, 2 ed., Santiago, Ediciones Jurídicas de Santiago, 2007, pp. 511 y ss.

Bustos, Juan y HormazáBAl, Hernán, Lecciones de derecho penal, vol. I., Madrid, Trotta, 1997.

Bustos, Juan y HormazáBal, Hernán, "Pena y Estado", en Papers, Revista de Sociología 13 (1980), pp .97 y ss.

Cerezo, José, Curso de derecho penal español. Parte general I. Introducción teoría del delito/ 1, 3 ed., Madrid, Tecnos, 1992.

Cervelló, Vicenta, Derecho penitenciario, Valencia, Tirant lo Blanch, 2001.

Córdoba, Juan, "La pena y sus fines en la Constitución española de 1978”, en Papers. Revista de Sociología 13 (1980), pp. 129 y ss.

De Rivacoba y Rivacoba, Manuel, "Introducción al estudio de los principios cardinales del derecho penal”, en Revista Brasileira de Ciencias Crimináis 32 (2000), pp. 39 y ss. 
Donini, Massimo, "Un derecho penal fundado en la carta constitucional: razones y limites. La experiencia italiana”, en vv.AA. Responsa Iurisperitorum Digesta, vol. II. Salamanca, Ediciones Universidad, 2001, pp. 223 y ss.

Donini, Massimo, Il volto attuale dell'illecito penale. La democracia penale tra differenzizione e sussidiarietà, Milán, Giuffrè, 2004, pp. 61 y ss.

Donini, Massimo, Teoria del reato. Una introduzione, Padova, Cedam, 1995.

Donini, Massimo, "Dogmatica penale e politica criminal a orientamento costituzionalistico. Conoscenza e controllo critico delle secelte di criminalizzazione”, en Dei delitte e delle pene3 (1998), pp. 37 y ss.

Durán, Mario, Introducción a la Ciencia jurídico-penal contemporánea. Santiago, Ediciones Jurídicas de Santiago, 1996.

Durán, Mario, "Constitución y legitimación teórica de la pena. Apuntes teleológicos sobre el rol de la Constitución en el sistema penal”, en Revista Politica Criminal 11 (2011), pp. 142-162.

DurÁn, Mario, "El derecho penal del enemigo. Formulación y observaciones críticas en el contexto del debate sobre la modernización y expansión del Derecho penal”, en Manuel Cancio Meliá (ed. y coord.), Derecho penal del enemigo. El discurso penal de la exclusión, Buenos Aires-Montevideo, B de F, Madrid, Edisofer, 2006, pp. 725 y ss.

Durán, Mario, "Prevención especial e ideal resocializador. Concepto, evolución y vigencia en el marco de la legitimación y justificación de la pena", en Revista de estudios criminológicos y penitenciarios 13 (2008), pp. 57 y ss.

DuRÁN, Mario, "Justificación y legitimación político-criminal de la pena. Concepto, criterios y orientaciones en la actual jurisprudencia nacional”, en Revista politica criminal 8 (2009), pp. 266-291.

DurÁN, Mario, “Teorías absolutas de la pena: origen y fundamentos. Conceptos y críticas fundamentales a la teoría de la retribución moral de Immanuel Kant a propósito del neo-retribucionismo y del neo-proporcionalismo en el derecho penal actual”. Revista de Filosofia 67 (2011), pp. 123-144.

DurÁn, Mario, "El planteamiento teleológico constitucional de la Escuela de Bologna y la obra de Franco Bricola como antecedentes históricos y metodológicos de la noción de Derecho Penal Constitucional”, en Revista de Derecho 2 (2013), pp. 305-326.

FERRAJoli, Luigi, Derecho y razón. Teoría del garantismo penal, Madrid, Trotta, trad. P. Andres, A. Ruiz, J. Bayón, J. Terradillos y R. Cantarero, 2000.

Foucault, Michael, Vigilar y castigar, 12 ed., Madrid, Siglo XXI, trad. Aurelio Garzón del Camino, 2000.

García ArÁn, Mercedes, Fundamento y aplicación de penas y medidas de seguridad en el código penal de 1995, Navarra, Aranzadi, 1997. 
Garcia-Pablos, Antonio, Tratado de Criminología, 3 ed. actualizada, corregida y aumentada, Valencia, Tirant lo Blanch, 2003.

García VAldÉs, Carlos, Teoría de la pena, 3 ed., Madrid, Tecnos, 1985.

García Rivas, Nicolás, El poder punitivo en el Estado democrático de derecho. Cuenca, U. de Castilla-La Mancha, 1996.

Hassemer, Winfried, "Prevención en el derecho penal", en Juan Bustos, (dir.), Prevención y teoría de la pena. Santiago, Editorial Jurídica Cono Sur, 1995, pp. 93 y ss.

Jescheck, Hans-Heinrich, Tratado de derecho penal. Parte general, Granada, Comares, trad. José Luis Manzanares, 1993.

Künsemuller, Carlos, "La judicialización de la ejecución penal", en Derecho penal y politica criminal. Compilación de artículos, Santiago, Legal Publishing, 2012, pp. 635 y ss.

Künsemuller, Carlos, "Importancia dogmática y político-criminal de los principios limitadores del ius puniendi", en Derecho penal y politica criminal. Compilación de artículos, Santiago, Legal Publishing, 2012, pp. 197 y ss.

KüNSEMUlLER, Carlos, "Praeter intentionem y principio de culpabilidad", en Derecho penal y política criminal. Compilación de artículos, Santiago, Legal Publishing, 2012, pp. 292 y ss.

Lamarca Pérez, Carmen, "Régimen penitenciario y derechos fundamentales", en EPC XVI (1993), pp. 220 y ss.

LuZÓn Peña, Diego-Manuel, "Principio de igualdad, derecho penal de hecho y prevención especial: equilibrio y tensiones”, en Adela ASÚA BATARRITA, (coord.), El pensamiento penal de Beccaria: su actualidad, Bilbao, U. de Deusto, 1990, pp. $67 \mathrm{y}$ ss.

Magariños, Mario, "Hacia un criterio para la determinación judicial de la pena", en AA.vv., Determinación judicial de la pena, Buenos Aires, Editores del Puerto, 1993, pp. 74 y ss

Marcilla, Gema, "Argumentación en el ámbito legislativo y prestigio de la ley penal”, Santiago Mir y Mirentxu Corcoy (dirs.), Constitución y sistema penal, MadridBarcelona, Marcial Pons, 2012, pp. 67 y ss.

Mir, Santiago, Introducción a las bases del derecho penal, Barcelona, Bosch, 1975.

Mir, Santiago, Derecho penal. Parte general, 5 ed., Barcelona, Reppertor, 2000.

Mir, Santiago, "Problemática de la pena y seguridad ciudadana", en El derecho penal en el Estado social y democrático de derecho, Barcelona, Ariel, 1994, pp. 126 y ss.

Mir, Santiago y Corcoy Mirentxu (dirs.), Constitución y sistema penal, MadridBarcelona, Marcial Pons, 2012. 
Moccia, Sergio, Il Diritto penale tra essere e valore. Funzione sistematica teleologica, Napoli, ESI, 1992.

Muñoz Conde, Francisco, Introducción al derecho penal, Barcelona, Bosch, 1976.

Muñoz Conde, Francisco y García Arán, Mercedes, Derecho penal. Parte general, Valencia, Tirant lo Blanch, 1994.

PRADO, Luiz Regis, Bien jurídico-penal y constitución, Lima, ARA, trad. Luis Alvarez Aranda, 2010.

Quintero, Gonzalo, "Determinación de la pena y política criminal”, en CPC 4 (1982), pp. 49 y ss.

Roxin, Claus, "La determinación de la pena a la luz de la teoría de los fines de la pena”, en Culpabilidad y prevención en el derecho penal, Madrid, Reus, trad. Francisco Muñoz Conde, 1981, pp. 46 y ss.

Roxin, Claus, Derecho penal. Parte general. Tomo I. Fundamentos. La estructura de la teoría del delito, Madrid, Civitas, trad. y notas Diego-Manuel Luzón Peña, Miguel Díaz y García Conlledo, Javier de Vicente Remesal, 1997.

Roxin, Claus, "Sentido y límites de la pena estatal", en Problemas básicos del derecho penal, Madrid, Reus, trad. y notas por Diego-Manuel Luzón Peña, 1976, pp. 15 y ss.

Roxin, Claus, "Franz von Liszt y la concepción político-criminal del proyecto Alternativo”, en Problemas básicos del derecho penal, Madrid, Reus, trad. y notas por Diego Manuel Luzón Peña, 1976, pp. 37 y ss.

Silva, Jesús-María, Aproximación al derecho penal contemporáneo, Barcelona, Bosch, 1992.

Stratenwerth, Günter, Derecho penal. Parte general. I. El hecho punible, Madrid, Edersa, Instituto de Criminología de la U. Complutense de Madrid, trad. de la 2 ed. alemana (1976) de Gladys Romero, 1982.

Tiedemann, Klaus, “Constitución y derecho penal”, en REDC 33 (1991), pp. 145-171.

TomÁs y Valiente, Francisco, La tortura en España, 2 ed., Barcelona, Ariel, 1994.

Tomás y Valiente, Francisco, El derecho penal de la monarquía absoluta. (siglos XVI, XVII y XVIII), 2 ed., Madrid, Tecnos, 1998.

ToRio López, Ángel, "La pena de muerte. Problemática histórica y contemporánea”, en Adela Asúa BATARRita (coord.), El pensamiento penal de Beccaria: su actualidad, Bilbao, U. de Deusto, 1990, pp. 95 y ss.

ToRio LóPez, Ángel, "La prohibición constitucional de las penas y tratos inhumanos o degradantes”, en Poder Judicial 4 (1986), pp. 69 y ss.

VASSALli, Giuliano, "I principi generali del Diritto nell'esperienza penalistica", en RIDPP (1991), pp. 699 y ss. 
Volk, Klaus, "Sistema penale e diritti dell'uomo", en Sergio MoccIa (a cura di), Diritti dell'uomo e Sistema Penale, vol. I, Napoli-Roma, Edizioni Scientifiche Italiane, 2002, pp. 93 y ss.

von LiszT, Franz, La idea del fin en el derecho penal. Programa de la Universidad de Marburgo, 1882, Granada, Comares, 1995.

ZAFFARONI, Eugenio Raúl, "El marco constitucional iushumanista del saber penal", en En torno de la cuestión penal. Colección Maestros del Derecho Penal, 18, Montevideo-Buenos Aires, B de F, 2005, pp. 121 y ss.

Zaffaroni, Eugenio, Alagia, Alejandro y Slokar, Alejandro, Manual de derecho penal. Parte general, 2 ed., Buenos Aires, Ediar, 2006.

ZIFFER, Patricia, "Consideraciones acerca de la problemática de la individualización de la pena”, en AA.vv., Determinación judicial de la pena, Buenos Aires, Editores del Puerto, 1993, pp. 91 y ss.

ZIPF, Heinz, Introducción a la política criminal, Jaén, Edersa, trad. Miguel Izquierdo Masias, Picavea, 1979.

Zugaldía, José Miguel, Fundamentos de derecho penal. Parte general. Las teorias de la pena y de la ley penal, Granada, U. de Granada, 1990.

Zúñiga Rodríguez, Laura, Politica Criminal, Madrid, Colex, 2001. 